\title{
Mapeamento dasUnidades deConservação das Regiões Norte e Noroeste do Estado do Rio de Janeiro
}

\author{
Fábio Freitas da Silva ${ }^{1}$ \\ Marlúcia Junger Lumbreras ${ }^{2}$ \\ Sérgio Henrique de Mattos Machado ${ }^{3}$ \\ Ana Paula Moura de Almeida ${ }^{4}$ \\ Ítalo de Oliveira Matias ${ }^{5}$ \\ Henrique Rego Monteiro da Hora ${ }^{6}$ \\ Milton Erthal Jr. ${ }^{*}$
}

\begin{abstract}
RESUMO
O objetivo deste trabalho foi avaliar a evolução e o panorama atual das Unidades de Conservação (UCs) do Brasil, com enfoque na mesorregião Norte e Noroeste do Estado do Rio de Janeiro. A pesquisa foi realizada a partir de dados disponibilizados pelo Ministério do Meio Ambiente, como a distribuição das UCs no território, processada por Sistema de Informação Geográfico, informações sobre sua área, data de criação, tipologias e gestão. A receita obtida pelo ICMS ecológico foi analisada no sítio do CEPERJ. A primeira UC criada nessa mesoregião foi o Parque Estadual do Desengano, em 1970. A partir da década de 1990 houve aumento significativo de UCs e atualmente existem 40, sendo 27 de Uso Sustentável, representadas, principalmente, pela categoria Reserva Particular do Patrimônio Natural. Na categoria Proteção Integral, os parques compõem a maior parte das UCs. A Região Noroeste tem $4 \%$ de sua área total protegida por UCs, enquanto que na Região Norte Fluminense este percentual é de $6 \%$. A presença de UCs tem auxiliado os municípios das regiões Norte e Noroeste quanto a captação do ICMS ecológico, totalizando cerca de R\$ 86 milhões desde 2009, o que é pouco representativo em relação aos outros municípios do estado do Rio de Janeiro. A Mata Atlântica presente nestes territórios é diversificada, com diferentes fitofisionomias, onde habitam espécies sob ameaça de extinção. A expansão da quantidade e uma boa gestão das UCs já existentes são meios para aumentar a arrecadação fiscal dos municípios e diminuir a fragilidade ambiental regional, fruto de uma ocupação desordenada do território. As UCs podem proporcionar serviços ambientais essenciais, como a diminuição das secas, enchentes e erosão do solo, problemas ambientais recorrentes nesta mesorregião.
\end{abstract}

PALAVRA-CHAVE: Desenvolvimento Regional; Sustentabilidade Ambiental, ICMS Ecológico, Biodiversidade, Mata Atlântica, Gestão Ambiental.

1 Doutorando em Planejamento Regional e Gestão da Cidade - Universidade Candido Mendes, Campos dos Goytacazes.

2 Professora do Instituto Federal Fluminense, campus Itaperuna; Doutoranda em Planejamento Regional e Gestão da Cidade - Universidade Candido Mendes.

3 Doutorando em Planejamento Regional e Gestão da Cidade - Universidade Candido Mendes, Campos dos Goytacazes

4 Médica dermatologista professora da Faculdade de Medicina de Campos; Doutoranda em Planejamento Regional e Gestão de Cidades - Universidade Candido Mendes, Campos dos Goytacazes.

5 Professor da Universidade Candido Mendes, Campos dos Goytacazes. Professor da Universidade Candido Mendes, Mestrado Profissional em Pesquisa Operacional e Inteligência Computacional e Doutorado em Planejamento Regional e Gestão da Cidade, Campos dos Goytacazes.

6 Professor do Instituto Federal Fluminense, Mestrado Profissional em Sistemas Aplicados a Engenharia e Gestão, Campos dos Goytacazes.

$7 \quad$ Professor do Instituto Federal Fluminense, Mestrado Profissional em Sistemas Aplicados a Engenharia e Gestão, Campos dos Goytacazes. Professor da Universidade Candido Mendes, Mestrado Profissional em Pesquisa Operacional e Inteligência Computacional e Doutorado em Planejamento Regional e Gestão da Cidade, Campos dos Goytacazes. *Autor para correspondência: miltonerthal@hotmail.com 


\begin{abstract}
The aim of this work was to evaluate the current scenario of the Protected areas (PAs) of Brazil, focusing on the mesoregion North and Northwest of Rio de Janeiro state. The research was conducted from data provided by the Ministério do Meio Ambiente, like distribution of PAs in the territory, processed by Geographic Information System, information on its area, date of creation, typologies and management. The revenue obtained from the ecological tax was analyzed on the CEPERJ website. The first PA created in this mesoregion was Desengano State Park in 1970. Since the 1990s there have been significant increases in PAs and there are currently 40, 27 of which are Sustainable Use, represented mainly by the Private Natural Heritage Reserve category. In the Integral Protection category, parks make up most of the PAs. The Northwest Region has $4 \%$ of its total area protected by PAs, while in the North Fluminense Region this percentage is $6 \%$. The presence of PAs has helped the municipalities of the North and Northwest regions in the capture of ecological tax, totaling about $\$ 86$ million since 2009, which is little representative compared to other municipalities in the state. The Atlantic Forest present in these territories is diverse, with different typologies, where inhabit species under threat of extinction. The expansion of the quantity and good management of existing PAs are means to increase the tax collection of the municipalities and reduce the regional environmental fragility, the result of a disorderly occupation of the territory. PAs can provide essential environmental services such as drought reduction, flooding and soil erosion, recurrent environmental problems in this mesoregion.
\end{abstract}

KEYWORDS: Regional development; Environmental Sustainability, Ecological tax, Biodiversity, Atlantic Forest, Environmental Management.

\title{
1- Introdução
}

A crescente preocupação com a preservação ambiental da sociedade a nível global, tem motivado a adoção de estratégia governamentais para a criação de áreas protegidas com o intuito de conservar atributos da natureza em longo prazo. Um dos principais avanços neste sentido foi a "Convenção Sobre a Diversidade Biológica", em 2002, quando os líderes mundiais se comprometeram com metas para reduzir a taxa de perda de biodiversidade (JEPSON et al., 2017). Estas ações resultaram no aumento do número de Unidades de Conservação (UCs), muitas localizadas em ecossistemas naturais altamente vulneráveis, que são essenciais para sustentar a biodiversidade e garantir os serviços ecossistêmicos (CAMPHORA \& MAY, 2006).

Apesar de haver um expressivo aumento no número total e extensão de áreas protegidas nos últimos anos, não há evidência de que este esforço venha contribuindo com a diminuição da taxa de perda de biodiversidade (BUTCHART et al., 2010), principalmente nos ambientes tropicais (BARLOW et al., 2018). Segundo estes autores, uma estimativa realizada com 31 indicadores permitiu constatar que aumentou o risco de extinção das populações estudadas. $\mathrm{O}$ aumento do consumo de recursos naturais, introdução de espécies invasoras, poluição por nitrogênio, sobre-exploração e as mudanças climáticas foram considerados os fatores mais importantes para o agravamento do problema (GELDMANN et al., 2014; LAURANCE e BALMFORD, 2013). Tal fato decorre da necessidade de expansão da extração de recursos naturais e de infraestrutura para suprir as necessidades das populações humanas (JEPSON et al., 2017). Estes argumentos reforçam a necessidade de adoção de várias ações, pois apenas a criação de UCs não é suficiente, para assegurar a proteção dos recursos naturais, culturais e históricos e biodiversidade.

Entendem-se como unidades de conservação, todas as áreas protegidas que possuem regras próprias de uso e de manejo, com a finalidade própria de preservação e proteção de espécies vegetais ou animais, de tradições culturais, de belezas paisagísticas, ou de fontes científicas, dependendo da categoria em que se enquadra (MEDEIROS, 2006).

No Brasil, a criação de UCs (são 12 categorias ao todo) não tem conseguido minimizar as pressões antrópicas que comprometem a conservação dos recursos naturais e culturais do país. Além de aumentar o número e melhorar a gestão das UCs, estas precisam sanar problemas de desmatamentos, invasões e a extração de produtos naturais (MILANO, 2000). Para minimizar este problema o governo brasileiro criou, em 2014, o "Sistema de Informação Sobre a Biodiversidade 
Brasileira" para sistematizar informações sobre a biodiversidade nacional. A iniciativa, no entanto, limita-se apenas em catalogar o que já se sabe sobre a fauna e a flora nativas (BARLOW et al., 2018).

O território do estado Rio de Janeiro está inserido nos biomas Mata Atlântica e Zona Costeira. O ambiente costeiro é uma faixa territorial, geologicamente muito ativa, entre o domínio continental e marinho. A Mata Atlântica é uma das áreas mais ricas em biodiversidade do planeta, apresentando altos níveis de endemia. No entanto, com apenas $12,5 \%$ de sua área preservada encontra-se em situação vulnerável e, por este motivo, é classificada como um Hotspot mundial. O equilíbrio destas áreas vem sendo ameaçado pela introdução de espécies exóticas, superexploração de recursos naturais (mineração, madeira, água e solo para a agricultura e agropecuária) urbanização desordenada, esgotamento sanitário precário, extinção de espécies nativas e a ocupação irregular do solo (CAMPANILI, PROCHOW, 2006; ALMEIDA, 2016; LINS-DE-BARROS, 2017).

A Mata Atlântica é formada por várias tipologias florestais (ou unidades fitogeográficas ou fitofisionomias) e formações de ecossistemas associados que incluem: Floresta Ombrófila Densa; Floresta Ombrófila Aberta; Floresta Ombrófila Mista; Mata de Araucária, Floresta Estacional Decidual; Floresta Estacional Semidecidual; Formações Pioneiras (Restinga, Manguezal, Campo Salino, vegetação com influência fluvial ou lacustre); Campos de Altitude, Campo Rupestre, Encraves de Cerrado e, Zonas de tensão ecológica (CUNHA \& GUEDES, 2013). Muitas destas tipologias ocorrem nas regiões Norte e Noroeste do Estado do Rio de Janeiro, no entanto, os domínios Floresta Ombrófila Densa e Densa de Terras Baixas, Floresta Estacional Semidecidual, Restingas e manguezais são os mais afetados por ações antrópicas (IBGE, 2000; VILLA, 2006; SLUYS, 2017).

A Bacia Hidrográfica do Baixo Paraíba do Sul e do rio Itabapoana são consideradas pelo Ministério do Meio Ambiente (MMA, 2013) de alta vulnerabilidade ambiental. Estes ambientes vêm, ao decorrer dos anos, sendo dizimados devido ao crescimento populacional, empreendimentos de grande porte, industrialização e desmatamento. Tendo em vista as exigências legais do Novo Código Florestal brasileiro, Lei 12.561 de 25 de maio de 2012 (BRASIL, 2012), e a instalação de empresas com projetos potencialmente poluidores na região Norte do estado do Rio de Janeiro, que exigem compensação ambiental, principalmente em decorrência da atividade agrícola, mineradora e portuária, é crescente a demanda regional por serviços de recuperação de áreas degradas. Este cenário pode contribuir para a expansão de áreas protegidas nestas regiões. Além disso, a Mata Atlântica que ocorre na mesoregião Norte e Noroeste Fluminense tem grau de importância "extremamente alta" e, portanto, tem especial importância para a criação de áreas protegidas (MMA, 2007).

Sabe-se que o Rio de Janeiro tem cerca de $20 \%$ do seu território ocupado por UCs. Isso pode ser considerado um importante avanço visto o alto grau de endemismo e diversidade biológica comprovada no estado (INEA 2015, SEA, 2015; COELHO et al., 2017). No entanto, tratando-se especificamente do processo de criação de UCs, sua manutenção e participação no desenvolvimento regional da mesoregião Norte e Noroeste Fluminense, as informações são poucas e dispersas na literatura. Por estas razões foram criadas as questões de pesquisa deste artigo. Quantas UCs existem, quando foram criadas e qual é sua extensão territorial? A área ocupada por UCs é suficiente para garantir efeitos benéficos para a sociedade (serviços ambientais, lazer, turismo, educação ambiental, conservação da biodiversidade, etc)? A captação de recursos financeiros procedentes do ICMS ecológico é significativa para promover o desenvolvimento regional? Quais são as tipologias destas unidade?

O objetivo deste trabalho foi mapear a evolução histórica da criação das UCs na mesorregião Norte e Noroeste do Estado do Rio de Janeiro. O número total de UCs, suas tipologias, área de abrangência e sua contribuição para captação de recursos financeiros procedentes do ICMS ecológico foram apurados e apresentados na forma de gráficos, mapas e tabelas.

A estrutura do artigo segue o modelo convencional de divulgação científica. Após uma introdução sobre o tema e a definição do objetivo da pesquisa, o artigo apresenta um referencial teórico que aborda o conceito e a importância das UCs sob a ótica biológica, ambiental e social. Em seguida, 
discute-se a Política Nacional de Meio Ambiente do Brasil e as principais leis que regulamentam o assunto. Por fim, fez-se uma breve discussão sobre o papel das UCs no desenvolvimento regional.

O terceiro tópico apresenta os métodos utilizados na coleta de dados, que consistiram na busca de informações georeferenciadas sobre as UCs brasileiras, com enfoque nas regiões Norte e Noroeste Fluminense. O sítio do Cadastro Nacional de Unidades de Conservação (MMA, 2019) foi acessado para obter os arquivos do tipo shapfile (.shp) e informações sobres as UCs catalogadas no Brasil, no estado do Rio de Janeiro e na mesoregião Norte (NF) e Noroeste (NOF) Fluminense. Dados sobre a distribuição dos recursos do ICMS ecológico foram levantados para se apurar como esse imposto vem cooperando no desenvolvimento regional.

Os resultados obtidos são apresentados em seguida, mostrando a cronologia da criação de UCs nas esferas federal, estadual e na mesoregião analisada. São apresentados dados sobre cada UC e o quanto de recurso financeiro foi atribuído aos municípios pelo incentivo coasiano do ICMS ecológico desde o início da sua distribuição, ano de 2009. Por fim, apresenta-se a conclusão do trabalho.

\section{2- Referêncial Teórico}

\section{1- UCs - Definição e Histórico}

A degradação ambiental ocorrida a nível mundial despertou um alerta, impulsionando a criação das primeiras normas nesse campo, o que demonstrou um aumento na conscientização ambiental (LOPES, 2013).

O Código Civil de 1916 foi, no Brasil, o pioneiro em relação à proteção ambiental e, em seguida, vários decretos foram criados. Ao tratar a questão da proteção da natureza como responsabilidade da União e dos Estados, a Constituição de 1934 passa a tratar a natureza como patrimônio nacional admirável a ser preservado. É nesse cenário que os principais dispositivos legais de proteção da natureza, que levaram à criação e consolidação das primeiras áreas protegidas, são criados no Brasil, sendo o Código Florestal (Decreto 23793-1934) o instrumento mais importante, definindo as bases para a proteção territorial dos principais ecossistemas florestais e demais formas de vegetação naturais do país (MEDEIROS, 2006).

Segundo Medeiros (2003) as áreas protegidas são espaços territorialmente demarcados cuja principal função é a conservação e/ou a preservação de recursos, naturais e/ou culturais, a elas associados. A sua criação denota importante estratégia de controle do território, uma vez que determina limites e dinâmicas de uso e ocupação específicos. O Brasil, sendo um dos países com maior biodiversidade do mundo, instituiu um sistema de áreas naturais protegidas, denominadas de Unidades de Conservação (UCs) que tem como finalidade principal resguardar ao máximo a diversidade dos ecossistemas e espécies existentes (TORRES, 2008).

Os ecossistemas fornecem serviços essenciais a sociedade e a criação de uma área protegida pelo poder público tem como missão a proteção da natureza para as gerações atuais e futuras. Segundo PRIMACK e RODRIGUES (2015), o valor de uma UC deve ser avaliado de forma direta e indireta. Os valores econômicos diretos são os produtos consumidos por populações que vivem dentro ou no entorno das UCs, como: lenha, madeira, castanhas, sementes, verduras, proteína animal, flora medicinal, peles, mel, ceras, tinturas naturais, fragrâncias, ceras, resinas, entre outros. Além disso, pode-se citar o turismo e a partição de receita tributária, como é o caso do ICMS verde, como formas de promover o desenvolvimento regional (MEDEIROS et al., 2011). Os serviços inditetos não são contabilizados no sentido econômico usual, como é o caso da polinização realizada por animais (insetos, morcegos, aves e roedores, principalmente), assimilação de CO2 e liberação de $\mathrm{O} 2$ pela atividade fotossintética, regularização dos recursos hídricos, controle da erosão, degradação e imobilização de poluentes, valor científico, educacional, entre outros. 
Quanto a proteção dos espaços territoriais, a publicação da Lei no 9.985 institui, em 18 de julho de 2000, o Sistema Nacional de Unidades de Conservação da Natureza (SNUC) definindo critérios e normas para a criação, implantação e gestão das Unidades de Conservação e buscando uma melhor gestão do patrimônio ambiental brasileiro (CAMARGO et al., 2002). O SNUC foi o marco inicial para o planejamento consistente da conservação do ponto de vista de ecossistema, consolidando uma nova atitude do Estado na relação com a sociedade no âmbito da conservação da natureza. Essa atitude cria assim, uma série de mecanismos que asseguram uma maior participação pública no processo de criação e gestão das áreas protegidas (INFORME NACIONAL, 2007).

As primeiras áreas de proteção ambiental foram estabelecidas no Brasil desde 1937, baseadas nos princípios do Código Florestal Brasileiro de 1934, entretanto, o SNUC representa o primeiro instrumento formal e unificado para Unidades de Conservação. Seu principal objetivo é definir e regulamentar as categorias de Unidades de Conservação nas esferas federal, estadual e municipal (RYLANDS, et al., 2005). A lei do SNUC foi criada como resposta à situação precária em que se encontravam muitas unidades e à falta de uma gestão ordenada das mesmas, sendo um importante ganho no que diz respeito à conservação ambiental (GELUDA et al., 2004).

As áreas protegidas, no Brasil, são representadas por diferentes tipologias e incluem não somente as Unidades de Conservação, mas também as Reservas Legais e as Áreas de Preservação Permanente, as Terras Indígenas e os sítios de proteção criados a partir de convenções e tratados internacionais - Reservas da Biosfera, Sítios do Patrimônio da Humanidade e Sítios Ramsar ${ }^{8}$ (MEDEIROS \& GRAY, 2006).

As Unidades de Conservação são conceituadas como: "Espaço territorial e seus recursos ambientais, incluindo as águas jurisdicionais, com características naturais relevantes, legalmente instituído pelo Poder Público, com objetivos de conservação e limites definidos, sob regime especial de administração, ao qual se aplicam garantias adequadas de proteção" (BRASIL, 2011).

As UCs são divididas pelo SNUC em dois grupos de acordo com suas características específicas: as de proteção integral, cujo principal foco é a conservação da biodiversidade, admitindo-se apenas o uso indireto dos seus recursos, excetuando-se casos previstos em Lei; e as de uso sustentável, que objetivam compatibilizar a conservação ambiental com o uso sustentável de parcela de seus recursos naturais, como observado no Quadro 1 (GELUDA et al., 2004). É importante ressaltar que a escolha da categoria de uma UC deve considerar as potencialidades de uso que a área oferece, de modo a promover o desenvolvimento local.

Todas as categorias de manejo de Unidades de Conservação podem ser abertas à visitação, com exceção das Estações Ecológicas e das Reservas Biológicas, unidades absolutamente restritivas, que permitem apenas e conforme o caso, o desenvolvimento de atividades de pesquisa científica e educação ambiental com prévia autorização do órgão ambiental (OLIVEIRA et al., 2010).

\section{2- Legislação}

Conforme o artigo 225 da Constituição Federal (BRASIL, 1988), todos têm direito ao meio ambiente ecologicamente equilibrado, bem de uso comum do povo e essencial à sadia qualidade de vida, impondo-se ao poder público e à coletividade o dever de defendê-lo e preservá-lo para as presentes e futuras gerações. Regulando esse artigo constituinte, apresentam-se uma lei e dois decretos lei. A lei $n^{\circ} 9.985$ de 18 de julho de 2000 (BRASIL, 2000) trata das disposições preliminares do sistema nacional de unidades de conservação da natureza (SNUC), das categorias de Unidades

8 Sítios Ramsar ou Convenção das Terras Úmidas preza pela proteção e uso sustentável das terras húmidas a partir de cooperações nacionais e internacionais. No Brasil, estes ambientes estão localizados nos estados do Amazonas, Mato Grosso, Rio Grande do Sul, Maranhão e Tocantins. 
de Conservação (UC), da criação, implantação e gestão, dos incentivos, isenções e penalidades, das reservas da biosfera abordando, também, as disposições gerais e transitórias do assunto. $O$ decreto n4.340 de 22 de agosto de 2002 (BRASIL, 2002) depõe sobre a criação de Unidade de Conservação, sobre subsolo e espaço aéreo, do mosaico de UC, do plano de manejo, do Conselho, da gestão compartilhada com Organizações da Sociedade Civil de Interesse Público (OSCIP), da autorização para a exploração de bens e serviços, da compensação por significativo impacto ambiental, do reassentamento das populações tradicionais, da reavaliação de unidade de conservação de categoria não prevista no sistema, das reservas da biosfera e das disposições finais. Já o decreto $n^{\circ}$ 5.746 de 5 abril de 2006 (BRASIL,2006) regulamenta o artigo 21 da lei $n^{\circ} 9.985$ de julho de 2000 que depõe sobre Reserva Particular do Patrimônio Natural, as RPPN.

\section{Quadro 1: Grupos e categorias das Unidades de Conservação no Brasil}

\begin{tabular}{|c|c|c|}
\hline Grupo & Categoria da UC & Objetivo da categoria \\
\hline \multirow{5}{*}{ Proteção Integral } & Estação Ecológica - Esec & Preservação e pesquisa científica \\
\hline & Reserva Biológica - Rebio & Preservação integral da biota \\
\hline & Parque Nacional - Parna * & $\begin{array}{l}\text { Preservação, pesquisa científica, lazer e } \\
\text { educação ambiental }\end{array}$ \\
\hline & Monumento Natural - MN & Preservar sítios naturais raros \\
\hline & Refúgio da Vida Silvestre - Revis & $\begin{array}{l}\text { Assegurar existência e reprodução de espécies } \\
\text { da fauna e/ou flora }\end{array}$ \\
\hline \multirow{7}{*}{ Uso Sustentável } & Área de Proteção Ambiental - APA & $\begin{array}{l}\text { Proteger a biodiversidade, disciplinar a } \\
\text { ocupação e assegurar a sustentabilidade no } \\
\text { uso de recursos naturais }\end{array}$ \\
\hline & Área de Relevante Interesse Ecológico - Arie & $\begin{array}{l}\text { Manter ecossistemas de importância regional/ } \\
\text { local e regular uso admissível }\end{array}$ \\
\hline & Floresta Nacional - Flona* & Uso sustentável de recursos florestais \\
\hline & Reserva Extrativista - Resex & $\begin{array}{l}\text { Assegurar uso sustentável dos recursos } \\
\text { naturais por populações tradicionais }\end{array}$ \\
\hline & Reserva de Fauna & $\begin{array}{l}\text { Estudos técnico-científicos sobre manejo dos } \\
\text { recursos faunísticos naturais }\end{array}$ \\
\hline & Reserva de Desenvolvimento Sustentável - RDS & $\begin{array}{l}\text { Proteger e assegurar meios de vida que já } \\
\text { contribuem para a conservação }\end{array}$ \\
\hline & Reserva Particular do Patrimônio Natural - RPPN & $\begin{array}{l}\text { Proteção em área particular, permitindo } \\
\text { pesquisa e uso turístico e educacional }\end{array}$ \\
\hline
\end{tabular}

Fonte: COPPETEC, 2014

As Unidades de conservação são compostas por 12 categorias cujos objetivos específicos se diferenciam quanto à forma de proteção e usos permitidos. Algumas necessitam de mais cuidados, pelas fragilidades e particularidades e outras podem ser usadas de forma sustentável e conservada ao mesmo tempo (BRASIL,2000). Como forma de potencializar o papel das UC, concebeu-se o Sistema Nacional de Unidades de Conservação (SNUC) que engloba as UC federais, estaduais e municipais. O SNUC foi criado por lei em 18 de julho de 2000 (lei $n^{\circ} 9.985 / 2000$ ) e normatizado por dois decretos, um de 22 de agosto de 2002 e outro de 5 abril de 2006 (decretos n 4.340 e n ${ }^{\circ} 5.746$, respectivamente) e é gerido pelas três esferas de governo possibilitando, além da conservação dos ecossistemas e da biodiversidade, gerar renda, emprego, desenvolvimento e favorecer uma efetiva melhora na qualidade de vida das populações locais e do país como um todo.

\section{3- Aspectos Específicos de TIB}

A legislação brasileira prevê e incentiva variadas atividades econômicas a serem empreendidas dentro das UC, como meio de colaborar com o desenvolvimento social, econômico e científico regional ao conciliar o uso sustentável do solo, da proteção da biodiversidade e da criação de oportunidades 
de emprego e renda (GURGEL Helen C. et al.,2011). Assim, representam uma função essencial para o desenvolvimento do país, visto que asseguram a qualidade e a quantidade de água disponível; possibilitam o desenvolvimento de fármacos e cosméticos; reduzem a emissão de CO2; permitem o aproveitamento para atividades turísticas, etc. (MEDEIROS e YOUNG, 2011).

Gurgel et al. (2011) ao pesquisarem o potencial econômico das áreas das UCs brasileiras, verificaram que apenas as reservas biológicas e as estações ecológicas - que correspondem a 11,67\% da área de UCs - apresentam restrições no que tange à geração imediata de renda. Entretanto, os $88,33 \%$ restantes, dedicados às UCs viabilizam a realização de diversas atividades econômicas (GURGEL et al., 2011). A título de exemplo pode-se apresentar a experiência bem-sucedida implementada na Reserva de Desenvolvimento Sustentável Mamirauá, onde a introdução de técnicas de manejo sustentável para a pesca de pirarucus possibilitou um aumento em torno de $1000 \%$ na renda dos pescadores, bem como quadruplicou o volume de peixe. (VIANA et al., 2007 apud GURGEL et al., 2011).

Por sua vez, Medeiros e Young (2011) afirmam ser possível calcular o valor econômico das UCs brasileiras, visto que as mesmas são responsáveis por uma ampla variedade de serviços ambientais, apesar de a maioria não gerar receitas próprias. Tal afirmação é respaldada baseando-se no Princípio do Valor Econômico Total, que preconiza que o valor de um recurso ambiental pode ser calculado pelo montante de bens e serviços por ele providos, mesmo se os benefícios recebidos não puderem ser expressos a preços de mercado, pois na ausência de preços são adotadas técnicas de valoração ambiental para conferir valores monetários aos referidos benefícios (MEDEIROS e YOUNG, 2011).

Todavia, a operacionalidade do referido cálculo é dificultada em virtude de depender do conhecimento da dinâmica ecossistêmica relacionada a quesitos físicos e naturais - abastecimento de produtos madeireiros e não-madeireiros, resultado econômico da visitação, diminuição de emissões de gases de efeito estufa, preservação da biodiversidade etc. Como muitas vezes não se dispõe do referido conhecimento, há grande limitação na efetivação do cálculo. E mesmo quando as variáveis são mensuráveis, constata-se que as informações não são coletadas em virtude de fatores tais como, falta de recursos financeiros e humanos (MEDEIROS e YOUNG, 2011). Além disso, não é permitida a múltipla contagem. Assim, o valor de um serviço conferido a uma UC não pode ser contabilizado por outra. Havendo serviços simultâneos, o valor do benefício deve ser repartido de acordo com a contribuição específica de cada UC (MEDEIROS e YOUNG, 2011).

Apesar de haver limitações, nota-se que a exploração de UCs se enquadra no conceito de desenvolvimento sustentável, que aflora na década de 1980, a partir da publicação do Relatório Brundtland, que o explica com simplicidade, sendo considerado como o desenvolvimento que"satisfaz as necessidades do presente sem comprometer a capacidade das gerações futuras satisfazerem as suas próprias necessidades" (NOSSO FUTURO COMUM, 1988). Para Sachs, "a adjetivação deveria ser desdobrada em socialmente includente, ambientalmente sustentável e economicamente sustentado no tempo" (SACHS, 2008, p.9-10).

\section{3- Metodologia}

Foi realizada uma busca exploratória documental no site do Ministério do Meio Ambiente http:// mapas.mma.gov.br/i3geo/datadownload.htm (MMA, 2019) para obter os mapas das UCs do Norte e Noroeste Fluminense. Assim, foi obtido o arquivo ESRI Shapefile das UCs que contém informações, como, ano de criação, tipologias (de acordo com o Quadro 1), órgão gestor e a distribuição espacial das unidades de conservação.

O arquivo shapfile (.shp) é um formato de dado espacial que armazena informações de atributos pertencentes as feições espaciais, sua geometria inclui um conjunto de coordenadas vetoriais (ESRI, 1998). Para a manipulação dos arquivos shapefile foi utilizado o Sistema de Informação Geográfica 
(SIG) Quantum GIS que é um software livre e de código aberto. Desta forma, foi possível explorar os dados e construir mapas personalizados, tabelas e gráficos de acordo com as categorias das UCS apresentadas na seção anterior. As UCs regionais foram estudadas quanto a sua denominação, área total, tipologias, ano de criação, esfera administrativa (federal, estadual ou municipal) e a existência de um Plano de Manejo e Conselho Gestor. A cronologia da área territorial ocupada por UCs federais, estaduais e municipais, desde a década de 1970 até o ano de 2017, foi avaliada.

As UCs podem contribuir de várias formas para o desenvolvimento regional, investigando-se o valor econômico direto e indireto. Neste trabalho avaliou-se como as UCs do Norte e Noroeste Fluminense vem cooperando para o recebimento de recursos tributários advindos do ICMS Ecológico do estado do Rio de Janeiro. Para isso, o sítio do CEPERJ foi acessado para avaliar como as UCs participam desta arrecadação, considerando-se as áreas protegidas em cada município da Região Norte (Campos dos Goytacazes, Carapebus, Cardoso Moreira, Conceição de Macabu, Macaé, Quissamã, São Fidelis, São Francisco do Itabapoana e São João da Barra) e Região Noroeste (Aperibé, Bom Jesus do Itabapoana, Cambuci, Italva, Itaocara, Itaperuna, Laje do Muriaé, Miracema, Natividade, Porciúncula, Santo Antônio de Pádua, São José de Ubá e Varre-sai). O valor do ICMS ecológico distribuído aos municípios considera em sua base de cálculo os seguintes aspectos: UCs ( $45 \%$ dos recursos), qualidade da água ( $30 \%$ dos recursos) e gestão dos resíduos sólidos (25\% dos recursos) (CEPERJ, 2019). Desta forma, analisou-se apenas a fatia relativa as UCs, que tem pontuação dupla: pontuação alta para as UCs municipais e pontuação baixa para o conjunto total das UCs presentes no município. Esta análise foi realizada desde o início da aplicação da lei do ICMS ecológico (2009) até a atualidade (outubro de 2019).

\section{4- Resultados e Discussões}

A primeira UC oficialmente constituída no Brasil foi a Reserva Biológica Estadual de Guaratiba, localizada na cidade do Rio de Janeiro, criada em 1914. Em seguida foram criadas a Floresta Nacional de Lorena, o Parque Nacional do Itatiaia e a Serra dos Órgão, em 1934, 1937 e 1939, respectivamente. Em contraste, no Norte e Noroeste Fluminense (NF e NOF) a primeira UC foi o Parque Estadual do Desengano, criado apenas em 1970, posteriormente, a Área de Proteção Ambiental do Arquipélago de Santana e da Lagoa de Cima surgiram, respectivamente, em 1989 e 1992 (FIGURA 1).

Parece não haver consenso sobre qual foia primeira UC brasileira, no entanto, alguns autores consideram - Parque Estadual de São Paulo, criado em 1896, e a implantação da floresta da Tijuca (atualmente Parque Nacional) como as primeiras iniciativas neste sentido (MEDEIROS, 2006). Historicamente, os estados do Rio de Janeiro e São Paulo se destacam no cenário nacional quanto as iniciativas para a criação de áreas protegidas. Graças ao protagonismo dos cidadãos fluminenses Alberto Torres e André Rebouças, influenciados, entre outras coisas, com a criação da primeira UC a nível mundial, o Parque de Yellowstone, em 1872, iniciou-se um processo de criação de UCs em território nacional (HAAG, 2010). Além disso, o estado tem, atualmente, 244 UCs, o que faz do Rio de Janeiro uma referência nacional quanto a criação de áreas protegidas.

O Rio de Janeiro é um dos estados da federação com maior diversidade de espécies (FORZZA et al., 2010) e um importante centro de endemismo no país (COELHO et al., 2017). Totalmente inserido no bioma Mata Atlântica, o estado faz parte da Reserva da Biosfera da Mata Atlântica/RJ (CAMPANILI e PROCHOW, 2006), o que implica na sua participação em uma rede global de intercâmbio e cooperação, voltada para promover o desenvolvimento sustentável, o conhecimento científico, a educação ambiental, a conservação da biodiversidade e a melhoria de qualidade de vida das populações (CASTRO, 2015). No entanto, apesar da notória importância, a conservação da biodiversidade no estado é considerada preocupante. A maior parte das 593 espécies da fauna que se encontram sob ameaça de extinção na Mata Atlântica, são endêmicas deste bioma (ICMBio/MMA, 2018).

Com 8.037 espécies de plantas catalogadas, a flora do Rio de Janeiro é considerada uma das mais ricas do Brasil (COELHO et al, 2017), incluindo cerca de 100 plantas de especial interesse para a conservação 
ou pesquisa científica (MARTINELLI e MORAES, 2013). As restingas, por exemplo, abrigam espécies de plantas raras, endêmicas e sob pressão da expansão urbana litorânea. No entanto, a lista com espécies da flora ameaçadas de extinção está em expansão no Estado. Em 2013 estimava-se 426 espécies ameaçadas (MARTINELLI e MORAES, 2013) e, mais recentemente, Coelho et al. (2017) aponta 17 plantas como extintas e outras 786 espécies com algum grau de vulnerabilidade.

A Floresta Estacional Semidecidual é uma tipologia muito pouco representada no sistema de UCs federais e estaduais. O índice de $17 \%$ em área preservada é uma referência importante para cobertura de áreas terrestres pelas UCs dos países e sub-regiões, por ter sido estabelecido pelas Metas de Aichi da Convenção das Nações Unidas sobre a Diversidade Biológica (COSTA, 2009; COELHO, et al., 2017).

A Figura 1 mostra três tipos de informação sobre o número de UCs ao longo dos anos. No o lado direito da Figura 1, na direção longitudinal, pode-se observar a cronologia da criação de UCs no Brasil e a expansão significativa que houve entre os anos de 2006 e 2013. Quanto as tipologias (parte superior da Figura 1, em intervalos decenais), observa-se que os parques e as Áreas de Proteção Ambiental (APA) são as categorias mais comuns e que as Reservas Particulares do Patrimônio Natural (RPPNs) aumentaram em número a partir dos anos 2000.

Figura 1: Cronologia da criação e diversificação (tipologias) das Unidades de Conservação (UCs) do Brasil e da mesoregião Norte (NF) e Noroeste (NOF) Fluminense. 0 Gráfico longitudinal expressa 0 número de UCs nacionais constituídas ao longo do tempo. 0 gráfico de barras superior apresenta, em intervalos decenais, a quantidade de UCs criadas no Brasil e suas tipologias. As mesmas informações são expressas no gráfico de barras inferior, com enfoque nas regiões NF e NOF. As linhas do gráfico inferior expressam a porcentagem da área ocupada pelas UCs do NF e NOF ao longo do tempo.
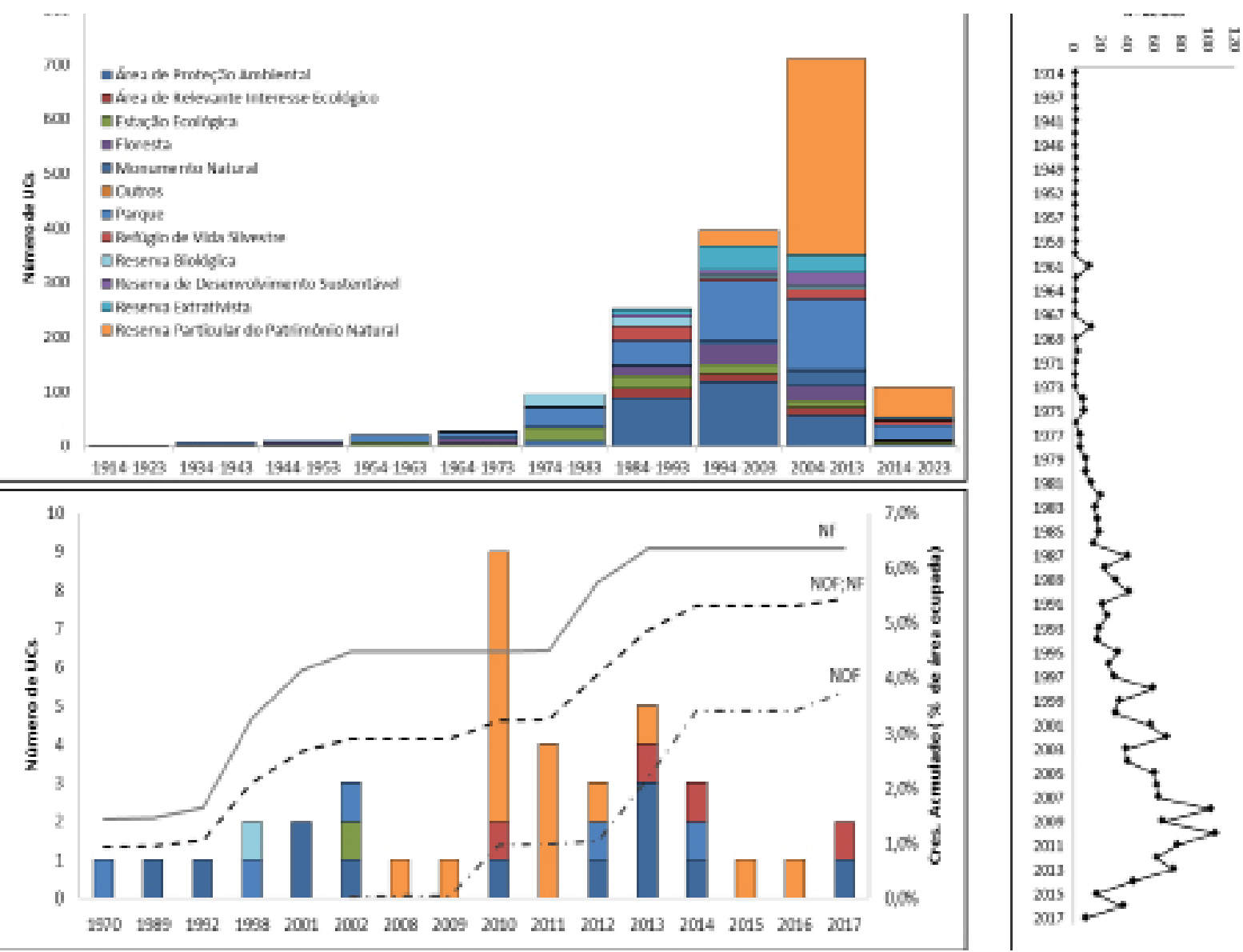

Fonte: Elaboração própria com dados do Ministério do Meio Ambiente (MMA, 2019). (http://mapas.mma.gov.br/i3geo/datadownload.htm) 
Este mesmo padrão pode ser visualizado no gráfico inferior da Figura 1, que apresenta as áreas protegidas na mesoregião NF e NOF ao longo do tempo. Entre 2010 e 2014 vinte e quatro UCs foram criadas, principalmente RPPNs e APA. As linhas do gráfico inferior mostram a evolução da área territorial protegida (\%) nas regiões NF e NOF. A região NF é pioneira na criação de UCs (Parque Estadual do Desengano em 1970) e atualmente tem 6\% do seu território ocupado por áreas protegidas. A criação de UCs no NOF só se inicia 30 anos depois, em 2002, e atualmente tem $4 \%$ do seu território ocupado por UCs.

A Figura 2 mostra a evolução da área total do território do NF e NOF ocupada por UCs. As UCs federais e estaduais, exclusivas do NF, abrange a maior porção do território, com 2.409,63 Km². A expansão das áreas federal e estadual foi mais expressiva a partir dos anos 2000 . As UCs municipais e as privadas (RPPNs) foram criadas a partir de 2010 e juntas somam 547,15 Km². A expansão das UCs municipais se inicia em 1990 e aumenta significativamente entre 2010 e 2015.

Figura 2: Ocupação territorial $\left(\mathrm{Km}^{2}\right)$ das Unidades de Conservação federais $(\mathrm{F})$, estaduais $(\mathrm{E})$, municipais (M) e Reserva Particular do Patrimônio Natural (RPPN) nas regiões Norte e Noroeste Fluminense, entre 1970 e 2019.

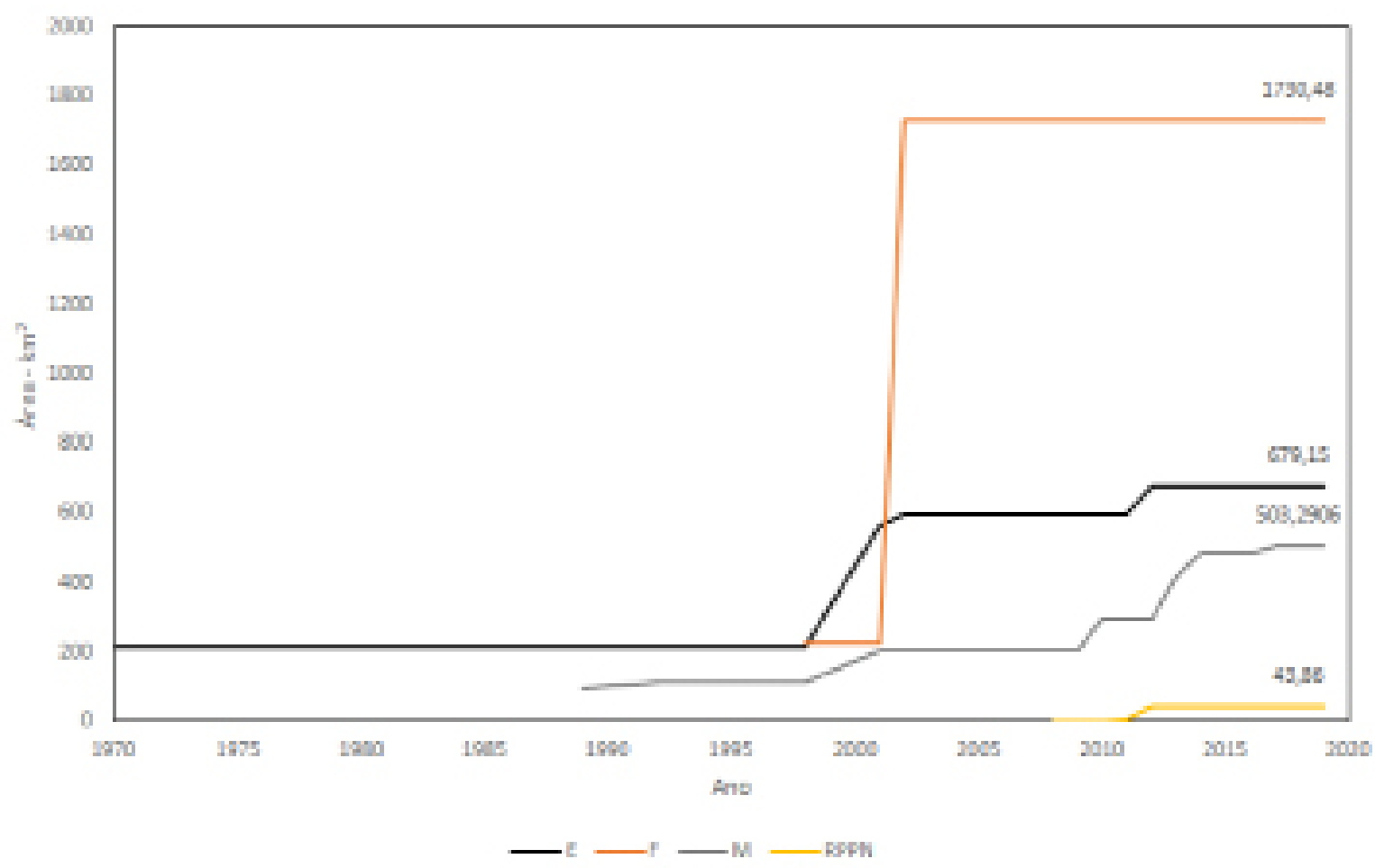

Fonte: Elaboração própria com dados do Ministério do Meio Ambiente (MMA, 2019). (http://mapas.mma.gov.br/i3geo/datadownload.htm)

A Tabela 1 sumariza as informações sobre as diferentes categorias de UCs no Brasil, no estado do Rio de Janeiro e na mesorregião NF e NOF. É possível observar que as UCs do tipo: Área de Proteção Ambiental (APA), Parques, e RPPNs são dominantes em relação as demais categorias. Ainda se constata que no Brasil as unidades de Uso Sustentável (US) representam 61\% (992 unidades) das UCs, enquanto as unidades de Proteção Integral (PI) são 39\% (630). As mesorregiões NF e NOF segue uma distribuição semelhante com $68 \%$ e $33 \%$, respectivamente. 
Tabela 1: Número e tipologias das Unidades de Conservação de Uso Sustentável (US) e Proteção Integral (PI) do Brasil, do estado do Rio de Janeiro (RJ) e nas regiões Norte (NF) e Noroeste (NOF) Fluminense.

\begin{tabular}{|c|c|c|c|c|}
\hline \multirow{2}{*}{ Tipo } & \multirow{2}{*}{ Categorias } & \multicolumn{3}{|c|}{ Unidades } \\
\hline & & Brasil & RJ & NF e NOF \\
\hline \multirow{6}{*}{ US } & Área de Proteção Ambiental & 275 & 62 & 10 \\
\hline & Área de Relevante Interesse Ecológico & 45 & 3 & - \\
\hline & Floresta Nacional & 99 & 1 & - \\
\hline & Reserva de Desenvolvimento Sustentável & 38 & 1 & - \\
\hline & Reserva Extrativista & 90 & 1 & - \\
\hline & Reserva Particular do Patrimônio Natural & 445 & 106 & 17 \\
\hline \multicolumn{2}{|c|}{ Subtotal } & 992 & 174 & 27 \\
\hline & Estação Ecológica & 95 & 3 & 1 \\
\hline & Monumento Natural & 41 & 7 & 2 \\
\hline & Parque & 379 & 48 & 5 \\
\hline & Refúgio de Vida Silvestre & 58 & 5 & 4 \\
\hline & Reserva Biológica & 57 & 7 & 1 \\
\hline \multicolumn{2}{|c|}{ Subtotal } & 630 & 70 & 13 \\
\hline & Outros & 2 & - & - \\
\hline Total & & 1624 & 244 & 40 \\
\hline
\end{tabular}

Fonte: Elaboração própria com dados do Ministério do Meio Ambiente (MMA, 2019).

(http://mapas.mma.gov.br/i3geo/datadownload.htm)

A Distribuição das UCs no território brasileiro pode ser visualizada no mapa da Figura 3. A região NF foi a que apresentou as maiores áreas territoriais de UCs mesclando várias categorias, enquanto as outras regiões têm uma predominância da categoria Área de Proteção Ambiental. Ao comparar as informações da Tabela 1 com o mapa em questão é possível observar um contraste, a Reserva Particular do Patrimônio Natural foi a que apresentou mais unidades, contudo ela não se destaca no mapa, logo há muita quantidade com pouca ocupação no espaço. Já a Área de Proteção Ambiental e os Parques corroborando com as informações em termos de unidade e espaço territorial. As mesorregiões NF e NOF apresentam certa diversificação, contém 6 de 11 categorias.

A Tabela 2 apresenta algumas características das 23 UCs sob responsabilidade administrativa de autarquias públicas nas regiões Norte $(n=13)$ e Noroeste Fluminense $(n=11)$. Existem 3 UCs federais e 4 estaduais, todas localizadas na região Norte Fluminense. A maior parte das UCs ( = 16) são administradas pelos municípios e apresentam evidências de gestões deficitárias, pois é frequente a ausência de um Conselho Gestor e do Plano de Manejo.

Com 305 UCs municipais, que juntas somam 455.850,42 ha, o Rio de Janeiro é o estado brasileiro que detém o maior número de unidades nesta categoria (SOS MATA ATLÂNTICA, 2017). A fragilidade na gestão das UCs municipais pode dificultar o alcance dos objetivos para os quais estas unidades foram criadas (preservação da biodiversidade, lazer, educação ambiental, recursos hídricos, etc), além do benefício fiscal do ICMS ecológico. Espera-se que as UCs contribuam para a sociedade de formas múltiplas e para isso elas precisam de uma boa gestão. Daí a importância da criação dos conselhos gestores e planos de manejo no interior das UCs e no seu entorno. 
Figura 3: Mapa do Brasil e do estado do Rio de Janeiro, com destaque no Norte (NO) e Noroeste Fluminense (NOF), mostrando a distribuição espacial das Unidades de Conservação no território e suas tipologias.

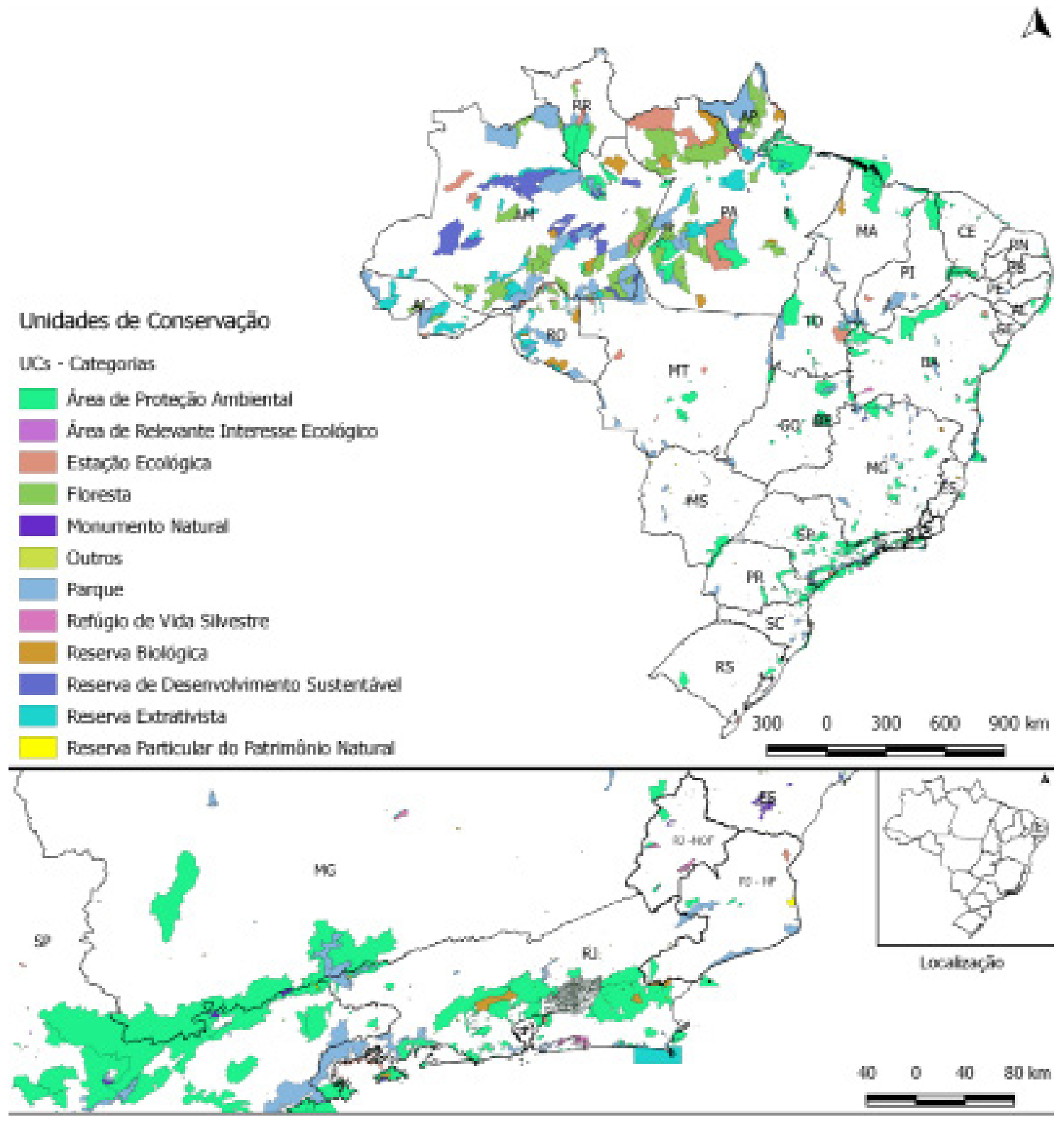

Fonte: Elaboração própria com dados do Ministério do Meio Ambiente (MMA, 2019). (http://mapas.mma.gov.br/i3geo/datadownload.htm)

Muitos autores concordam que a lei do ICMS ecológico do estado do Rio de Janeiro é a principal razão que justifica a expansão do número de UCs Municipais a partir de 2009 (CONTI, 2015, SOS MATA ATLÃNTICA, 2017; SILVA, 2018). Os dados apresentados na Tabela 3 corroboram estas opiniões, pois nas regiões NF e NOF as Ucs Municipais surgem de forma expressiva a partir de 2010. As Áreas de Proteção Ambiental e os Refúgios da Vida Silvestre são as categorias de UCs Municipais mais corriqueiras na mesoregião NF e NOF.

É de se esperar que a maioria dos municípios tenham limitações para a gestão das UCs Municipais. Outro desafio adicional para as UCs Municipais é o tamanho reduzido das unidades e sua inserção em ambientes urbanos e periurbanos. Essas características exigem ações de manejo de maior complexidade, além de uma visão mais integrada do sistema (castro, 2015; CONTI, 2017; SOS MATA ATLÂNTICA, 2017). 
Tabela 2: Alguns atributos das Unidades de Conservação (UC) da esfera pública das regiões Norte e Noroeste do estado do Rio de Janeiro cadastradas em MMA (2019). Foram coletados dados sobre: nome da UC, ano de criação (AC), presença (+) ou ausência (-) do Conselho Gestor (CG) e do Plano de Manejo (PM), a região onde está localizada (NF = Norte Fluminense; NOF = Noroeste Fluminense), a esfera administrativa pública responsável $\left(F=\right.$ Federal; $E=$ Estadual; $M=$ Municipal) e a área $\left(\mathrm{Km}^{2}\right) \mathrm{da}$ UC.

\begin{tabular}{|c|c|c|c|c|c|c|}
\hline AC & Nome da UC & CG & PM & Região & Esfera & Área $\left(\mathbf{k m}^{2}\right)$ \\
\hline 1970 & Parque Estadual do Desengano & + & + & $\mathrm{NF}$ & $\mathrm{E}$ & 214,04 \\
\hline 1989 & Área de Proteção Ambiental do Arquipélago de Santana & - & - & NF & M & 94,66 \\
\hline 1992 & Área de Proteção Ambiental da lagoa de cima & + & - & NF & M & 17,08 \\
\hline 1998 & Parque Nacional Restinga de Jurubatiba & + & + & NF & $\mathrm{F}$ & 149,19 \\
\hline 1998 & Reserva Biológica União & - & - & NF & $\mathrm{F}$ & 77,56 \\
\hline 2001 & Área de Proteção Ambiental de Macaé de cima & + & + & NF & $\mathrm{E}$ & 350,03 \\
\hline 2001 & Área de Proteção Ambiental do Sana & + & - & NF & M & 91,46 \\
\hline 2002 & $\begin{array}{l}\text { Área de Proteção Ambiental da Bacia do Rio São João } \\
\text { (mico leão) }\end{array}$ & + & + & NF & $\mathrm{F}$ & $1.503,73$ \\
\hline 2002 & Estação Ecológica Estadual de Guaxindiba & + & + & $\mathrm{NF}$ & $\mathrm{E}$ & 32,59 \\
\hline 2002 & Parque Natural Municipal Sabiá-laranjeira de Rosal & - & - & NOF & M & 0,9395 \\
\hline 2010 & Área de Proteção Ambiental Miracema & - & - & NOF & M & 67,81 \\
\hline 2010 & Refúgio de Vida Silvestre da Ventania & - & - & NOF & M & 22,12 \\
\hline 2012 & Monumento Natural Municipal da Serra da Bolívia & - & - & NOF & M & 3,32 \\
\hline 2012 & Parque Estadual da Lagoa do Açu & + & - & NF & $\mathrm{E}$ & 82,49 \\
\hline 2013 & Área de Proteção Ambiental da Serra da Bolívia & - & - & NOF & M & 16,64 \\
\hline 2013 & Área de Proteção Ambiental Rio do Colégio & - & - & NF & M & 53,76 \\
\hline 2013 & $\begin{array}{c}\text { Área de Proteção Ambiental Serra do Itaóca (Waldeir } \\
\text { Gonçalves) }\end{array}$ & + & - & NF & M & 6,17 \\
\hline 2013 & Refúgio de Vida Silvestre do Chaua & - & - & NOF & M & 44,33 \\
\hline 2014 & Área de Proteção Ambiental Raposo & + & - & NOF & M & 61,61 \\
\hline 2014 & Parque Natural Municipal de Itaperuna & - & - & NOF & M & 0,1355 \\
\hline 2014 & Refúgio de Vida Silvestre do Sagui da Serra Escuro & - & - & NOF & M & 4,9156 \\
\hline 2017 & Monumento Natural Municipal da Floresta & - & - & NOF & M & 12,7 \\
\hline 2017 & Refúgio de Vida Silvestre Monte Alegre (Alírio Braz) & - & - & NOF & M & 5,64 \\
\hline
\end{tabular}

Legenda: NF = Norte Fluminense; NOF = Noroeste Fluminense; CG = Conselho Gestor; PM = Plano de Manejo; $A C=$ ano de criação; + = presença; - = ausência; Esfera administrativa = Federal (F), Estadual $(E)$ e Municipal (M).

Fonte: Elaboração própria com dados do Ministério do Meio Ambiente (MMA, 2019).

A Tabela 3 mostra as RPPNs legalmente estabelecidas nas regiões NF e NOF do estado. Nesta categorias, reservas particulares, as áreas das unidades são mais reduzidas em comparação com as UCs públicas, listadas na Tabela 2. Assim como as UCs municipais, as RPPNs são mais frequentes na região Noroeste. A Fazenda Caruara, localizada na zona costeira e restinga de São João da Barra, se diferencia com uma área de $38,44 \mathrm{Km}^{2}$, pois a maioria das RPPNs tem menos de $0,9 \mathrm{Km}^{2}$. Segundo o Cadastro Nacional de Unidades de Conservação (MMA, 2019) nenhuma RPPN pesquisada tem Plano de Manejo e Conselho Gestor instituídos. Esta observação é um alerta aos gestores públicos quanto a gestão destas unidades. Muitas foram criadas a mais de 5 cincos e, por lei, deveriam ter ao menos o Plano de Manejo elaborado e implementado. Em um levantamento publicado em 2016 (INEA 2016), sobre as áreas legalmente protegidas do estado, existiam aproximadamente 462.000 ha, que correspondem a 19 Unidades de Conservação federais e 36 estaduais. 
Tabela 3: Nome, ano de criação $(\mathrm{AC})$ e área $\left(\mathrm{Km}^{2}\right)$ das Reservas Particulares do Patrimônio Natural (RPPN) localizadas nas regiões Norte (NF) e Noroeste (NOF) do estado do Rio de Janeiro (MMA, 2019).

\begin{tabular}{|c|c|c|c|}
\hline AC & Nome da RPPN & Região & Área (km $)$ \\
\hline 2008 & RPPN Reserva Florestal Engenheiro João Furtado de Mendonça & NOF & 0,84 \\
\hline 2009 & RPPN Boa Vista e Pharol & NOF & 0,08 \\
\hline 2010 & RPPN das Orquídeas & NOF & 0,06 \\
\hline 2010 & RPPN Douglas Vieira Soares & NOF & 0,18 \\
\hline 2010 & RPPN Frilson Matheus Vieira & NOF & 0,15 \\
\hline 2010 & RPPN Ribeira e Soledade & NOF & 0,06 \\
\hline 2010 & RPPN Xodó & NOF & 0,07 \\
\hline 2010 & RPPN Águas Claras I & NF & 0,02 \\
\hline 2010 & RPPN Itacolomy & NF & 0,01 \\
\hline 2011 & RPPN Boa Vista & NOF & 0,54 \\
\hline 2011 & NOF & 0,25 \\
\hline 2011 & RPPN Dr. Carlos De Oliveira Ramos & NOF & 0,03 \\
\hline 2011 & RPPN Sítio Palmeiras & NF & 2,48 \\
\hline 2012 & RPPN Ponte Do Baião & NF & 38,44 \\
\hline 2013 & RPPN Fazenda Caruara & NF & 0,1 \\
\hline 2015 & RPPN Mario e Alba Corral & NOF & 0,24 \\
\hline 2016 & RPPN Valério Cardoso Furtado & NF & 0,31 \\
\hline
\end{tabular}

Fonte: Elaboração própria com dados do Ministério do Meio Ambiente (MMA, 2019).

No NOF Área de Proteção Ambiental e Reserva Particular do Patrimônio Natural possuem as maiores áreas, $93,67 \mathrm{~km}^{2}$ e 103,3 km² ; já o NF a Área de Proteção Ambiental e Parques possuem as maiores extensões territoriais $176,15 \mathrm{~km}^{2}$ e $404,57 \mathrm{~km}^{2}$, respectivamente. A Reserva Particular do Patrimônio Natural tem um maior número de unidades, porém foi pouco expressiva em relação à área ocupada (Tabela 2 e 3).

Por fim, um comparativo das áreas totais das mesorregiões NF e NOF com as das UCs situadas nelas. O NOF possui uma extensão de $5.795,67 \mathrm{~km}^{2}$, as UCs desta mesoregião equivalem a $217,74 \mathrm{~km}^{2}$, isto é, $4 \%$ do território; enquanto o NF possui uma extensão de $10.548,43 \mathrm{~km}^{2}$ e UCs equivalentes a $670,81 \mathrm{~km}^{2}$, ou seja, $6 \%$ da área. Portanto, há uma expressiva distorção entre a média de áreas protegidas no estado do Rio de janeiro, que é de cerca de $20 \%$ (CASTRO, 2015), em relação ao quantitativo das áreas ocupadas por UCs no NF e NOF.

As regiões Norte e Noroeste do são os locais mais críticos do Rio de Janeiro quanto a presença de florestas contínuas, erosão do solo, degradação e conservação (CAMPANILI e PROCHOW, 2006). A fitofisionomia predominante no NF e NOF é a Floresta Estacional Semidecidual. Mais de $70 \%$ do território sob ocorrência desta tipologia florestal não possuem cobertura original, incluindo no interior das áreas legalmente protegidas (COSTA et al., 2009).

Um problema específico do Noroeste Fluminense é a falta de conhecimento sobre a flora regional. Os municípios de Aperibé, Italva, Laje de Muriaé, Miracema, Natividade e São José de Ubá tem informações muita escassas sobre sua flora. Esses municípios sofrem com extrema degradação dos ecossistemas naturais, atividades agropastoris e baixa densidade de UCs em seus territórios (COELHO et al., 2017).

Algumas das espécies da fauna ameaçadas de extinção ocorrem nessas regiões, como a jacutinga (Aburria jacutinga), o cágado-do-paraíba (Mesoclemmys hogei), o surubim-doparaíba (Steindachneridion parahybae), o macaco monocarvoeiro (Brachyteles arachnoides), o tatu-canastra (Priodontes maximus) e a formiga cortadeira Atta robusta (TEIXEIRA et al., 2003; SEA, 2015). 
A Tabela 4 apresenta os órgãos gestores das UCs do NF e NOF, bem como o número de unidades e áreas incumbidas a cada um. O Instituto Estadual do Ambiente do Rio de Janeiro (INEA) é, atualmente, responsável pela maior quantidade de UCs, totalizando uma área de 324,79 $\mathrm{km}^{2}$. Em seguida, destaca-se o Instituto Chico Mendes de Conservação da Biodiversidade (ICMBio) que é da instância federal e possui uma área de $173,08 \mathrm{~km}^{2}$, com apenas 4 unidades de conservação instituídas. A Secretaria Municipal de Ambiente e Sustentabilidade de Macaé e Secretaria Municipal do Ambiente de Itaperuna foram responsáveis por uma área de 90,17 $\mathrm{km}^{2}$ e $91,39 \mathrm{~km}^{2}$. Os demais órgãos não foram tão expressivos com os citados. É importante ressaltar que a apesar da esfera municipal coordenar uma menor área, o município pode conter outras UCs com áreas maiores ou não que não são de sua responsabilidade.

Tabela 4: Órgãos gestores das Unidades de Conservação do Norte e Noroeste Fluminense.

\begin{tabular}{|c|c|c|}
\hline Órgão Gestor & Área & Uni. \\
\hline Instituto Estadual do Ambiente do Rio de Janeiro & 324,79 & 20 \\
\hline Instituto Chico Mendes de Conservação da Biodiversidade & 173,08 & 4 \\
\hline Secretaria Municipal de Ambiente e Sustentabilidade de Macaé & 92,17 & 2 \\
\hline Secretaria Municipal do Ambiente de Itaperuna & 91,39 & 5 \\
\hline Prefeitura Municipal de São Fidélis/Secretaria de Desenvolvimento Ambiental & 58,18 & 1 \\
\hline Secretaria Municipal de Meio Ambiente de Miracema & 53,35 & 2 \\
\hline Prefeitura Municipal de Cambuci & 47,88 & 1 \\
\hline Prefeitura Municipal de Campos dos Goytacazes & 25,16 & 2 \\
\hline Secretaria Municipal do Ambiente de Aperibé & 21,59 & 2 \\
\hline Prefeitura Municipal de Bom Jesus do Itabapoana & 1,01 & 1 \\
\hline
\end{tabular}

Fonte: MMA (2019).

O SNUC protege cerca de 1,5 milhão de quilômetros quadrados do território brasileiro e integra sob o mesmo marco legal unidades de conservação federais, estaduais e municipais. A gestão desse território é um enorme desafio considerando a dimensão do Brasil e a ampla variedade de ecossistemas naturais e de contextos socioeconômicos (ICMBio, 2018). A falta completa ou deficiência administrativa na gestão de muitas UCs é um dos principais fatores que colabora para a degradação florestal no estado. As atividades agrícolas e pastoris, expansão urbana, queimadas, extrativismo mineral e do patrimônio genético, o setor energético e a falta de zoneamento ecológico-econômico também colaboram para o quadro de desflorestamento (CAMPANILI e PROCHOW, 2006).

Os gráficos da Figura 4 mostram os valores arrecadados com a distribuição do ICMS ecológico, referente apenas a implantação de UCs Municipais e o somatório de todas juntas. Este procedimento foi adotado pelo fato destas duas dimensões serem consideradas separadamente na fórmula que calcula o valor do ICMS ecológico correspondente a cada município. Desde 2014, observa-se uma distribuição equitativa das receitas advindas das UCs Municipais nas regiões NF e NOF, entre 1 e 2 milhões de reais anuais. A região Norte se destaca na dimensão número total de UCs e, por esta razão, arrecada cerca de 4 vezes mais do que a região Noroeste. 
Figura 4: Distribuição de receitas tributárias do ICMS ecológico, considerando-se apenas as dimensões referentes as Unidades de Conservação (UCs) Municipais e totais, desde $o$ início da sua implantação (2009) até a atualidade (2019). O estudo compreendeu os municípios das regiões Norte (NF) e Noroeste (NOF) do estado do Rio de Janeiro.
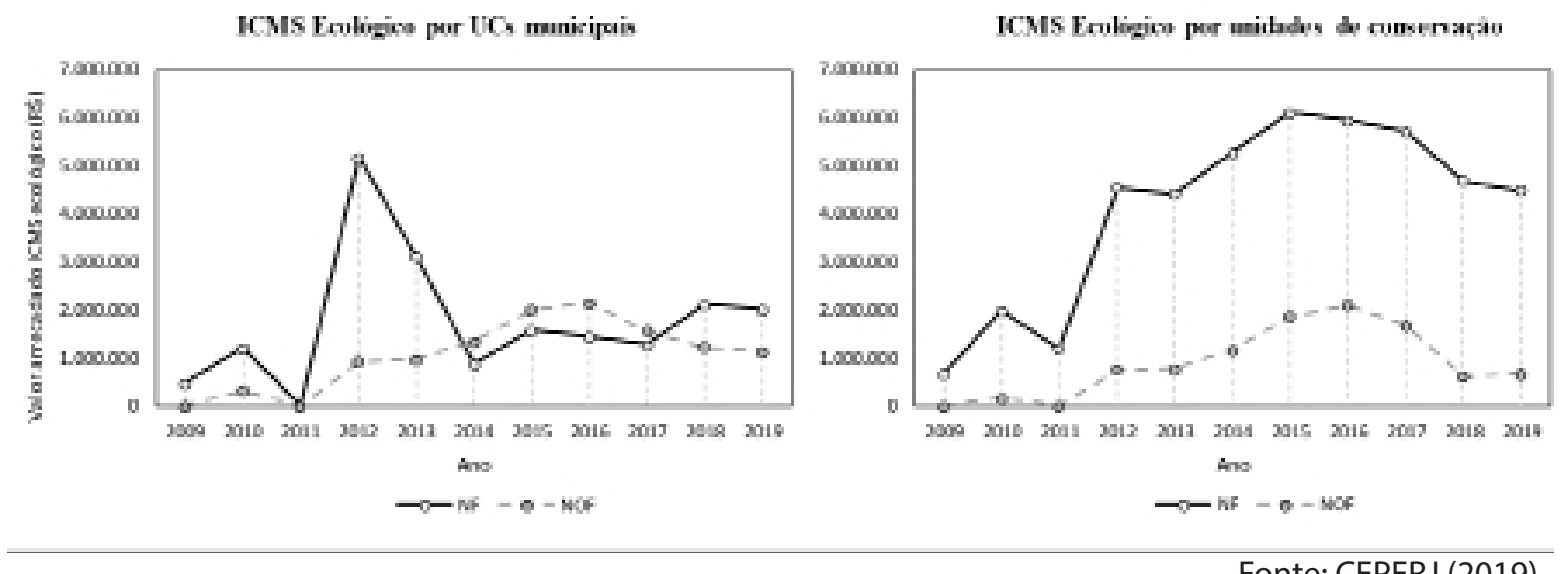

O ICMS ecológico já distribuiu mais de R\$ 86 milhões aos municípios da mesoregião em estudo. Observa-se na Tabela 5 que as UCs totais são responsáveis pela captação de mais de 50 milhões de Reais durante os 10 anos de avaliação, que se iniciou em 2009. Os municípios da região Norte, ao longo desses anos, foram recompensados com cerca de 65 milhões de Reais do ICMS ecológico, enquanto que no Noroeste o beneficiou foi de cerca de 22 milhões de Reais.

Tabela 5: Distribuição de valores do ICMS Ecológico nas mesorregiões Norte (N) e Noroeste (NOF) Fluminense entre os anos de 2009 e 2019.

\begin{tabular}{|c|c|c|}
\hline Mesoregião & ICMS Ecológico por UCs & ICMS Ecológico por UCs municipais \\
\hline NF & $45.082 .707,42$ & $19.304 .675,12$ \\
\hline NOF & $9.848 .496,38$ & $11.668 .026,80$ \\
\hline Total & $\mathbf{5 4 . 9 3 1 2 0 3 , 8 0}$ & $\mathbf{3 0 . 9 7 2 7 0 1 , 9 2}$ \\
\hline
\end{tabular}

Fonte: MMA (2019).

O ICMS ecológico é um instrumento Coasiano de compensação ou incentivo financeiro para os municípios que adotam estratégias de proteção da natureza, entre elas a criação de unidades de conservação (BRITO e MARQUES, 2017). No estado do Rio de Janeiro o ICMS ecológico foi instituído pela Lei . $^{\circ}$ 5.100, de 2007. Esta lei e um decreto suplementar (Decreto estadual n. ${ }^{\circ} 41.844$, de 4 de maio de 2009) definiram que $2,5 \%$, sobre a parcela de $25 \%$ de ICMS repassada aos municípios, deveria ser destinado segundo critérios ambientais (CONTI, 2017). O Decreto de 2009 propõe que o valor do ICMS ecológico deve ser definido conforme o cálculo do Índice Final de Conservação Ambiental (IFCA) do município. O IFCA é composto por três dimensões temáticas. A dimensão"Áreas Protegidas" é considerada a mais importante, pois tem peso de $45 \%$ no cálculo do ICMS ecológico; $30 \%$ do peso está associado a qualidade ambiental dos recursos hídricos; e $25 \%$ referentes à gestão dos resíduos sólidos (CONTI et al., 2015).

A dimensão temática "Áreas Protegidas" (45\% do peso) se subdivide em dois componentes: a) UCs totais e b) UCs Municipais. Desta forma as UCs municipais são contabilizadas duas vezes no cálculo do ICMS ecológico. Esse fato pode ter influenciado os gestores públicos municipais das regiões Norte e Noroeste Fluminense para criarem esta categoria de UC, um processo que já vem sendo observado em todo o Estado do Rio de Janeiro (CASTRO et al., 2015; CONTI, 2017; SILVA, 2018).

Segundo SILVA (2018), os municípios que menos arrecadam com o ICMS ecológico no estado, estão localizados na região Noroeste Fluminense, são eles: Cardoso Moreira, Cambuci, Bom Jesus do Itabapoana, Varre-sai, Italva, Itaperuna, Itaocara, Santo Antônio de Pádua, Porciúncula e Laje do Muriaé. 
No entanto, não há consenso quanto a utilização dos benefícios tributários do ICMS ecológico pelos municípios beneficiados. Muitos municípios, mesmo tendo em seus territórios extensas áreas protegidas, não apresentam bons indicadores orçamentários (SOS MATA ATLÂNTICA, 2017). Silva (2018) argumenta que, em alguns casos, a existência de UCs municipais não significa, necessariamente, um bom desempenho dos municípios com relação à gestão destas unidades. $\mathrm{A}$ autora destaca, por exemplo, o caso do município de Conceição de Macabu, no Norte Fluminense, que tem uma UC municipal que abrange quase a área total do município. No entanto, não há garantias que este município está realmente comprometido com a proteção dos recursos naturais desta UC.

Portanto, cada município deve fazer simulações para a criação de novas UCs, com base no índice de cálculo IFCA do ICMS ecológico do Rio de Janeiro, para prever o possível incremento de receita, considerando nesta decisão os gastos necessários para criar e mantar administrativamente uma futura UC.

O ICMS ecológico é um importante meio para atrair recursos e promover o desenvolvimento regional dos municípios que adotam políticas públicas voltadas para a criação e gestão de áreas protegidas. Porém, o trabalho de MEDEIROS et al. (2011) destaca muitas outras possibilidades de promoção do desenvolvimento. Segundo estes autores as UCs proporcionam bens e serviços diretos ou indiretos para as necessidades da sociedade brasileira, como a água para consumo humano, produção de energia, madeira e atividades de turismo e ecoturismo. Ostros aspectos como: controle da erosão, manancial de inimigos naturais para o controle de pragas, controle da poluição e um banco genético são aspectos relevantes de bens e serviços ambientais que podem dinamizar as economias locais, com valor de bilhões de reais.

\section{5- Conclusões}

O protagonismo do Rio de Janeiro a nível nacional quanto a criação de áreas protegidas não teve influência imediata nas regiões Norte e Noroeste do estado. O processo de criação de UCs na mesoregião estudada se iniciou na década de 1970 com a criação do Parque Estadual do Desengano, que protege uma área de floresta ombrófila densa. O incremento do número de UCs nessa mesoregião foi intensificado no fim da década de 1990, mas foi a partir de 2010 que atingiu seu ápice. Atualmente, existem 40 UCs na mesoregião, com predomínio das categorias Área de Proteção Ambiental (públicas), Parques (públicos) e Reserva Particular do Patrimônio Natural (privadas). No Brasil as unidades de Uso Sustentável representam $61 \%$ das UCs, enquanto as unidades de Proteção Integral são $39 \%$. A mesorregião NF e NOF segue uma distribuição semelhante com $68 \%$ e $33 \%$ respectivamente.

As unidades federais ocupam as maiores áreas $\left(1730,48 \mathrm{Km}^{2}\right)$, seguida das áreas estaduais $\left(679,15 \mathrm{Km}^{2}\right)$, que são geridas, respectivamente, pelo INEA e o ICMBio. As áreas ocupadas por UCs municipais e RPPNs ainda são pouco expressivas em relação as duas primeiras, mas estão em expansão. A região Norte tem mais tipologias e maiores áreas territoriais ocupadas por UCs, $6 \%$ ao todo ou $670,81 \mathrm{~km}^{2}$. No Noroeste, predominam as APAs e RPPNs e apenas $4 \%$ do território ocupado por UCs $\left(217,74 \mathrm{~km}^{2}\right)$. Estas unidades são fragilizadas quanto a sua gestão, pois a maioria não tem Plano de Manejo nem Conselho Gestor.

O esforço para a ampliação de UCs e sua diversificação nas regiões Norte e Noroeste Fluminense, além de garantir a proteção da Mata Atlântica nativa, poderá cooperar para o desenvolvimento regional. Os efeitos positivos da criação de UCs são o recebimento de tributos do ICMS Ecológico, os serviços ambientais prestados (água, lazer, controle biológico de pragas, contenção da erosão, assimilação dos gases estufa, etc), pelo aumento no turismo, fomento à pesquisa científica e investimentos diretos em infraestrutura para atender as UCs. 
Proporcionalmente, o Norte e o Noroeste recebem muito pouco da fatia do ICMS ecológico do estado. A criação de UCs pode amenizar este problema.

Uma das coisas que melhora a qualidade de vida da população é o contato com ambientes naturais. A criação de UCs e melhoria da gestão das já existentes é uma forma de atender este princípio. As áreas arborizadas, com infraestrutura para o acesso da população oportunizam a fuga do ambiente urbano construído e contato com a natureza (LONDE e MENDES, 2014). Vivem na mesoregião NF e NOF, aproximadamente, 1.300 .000 habitantes (FIRJAM, 2015; SEBRAE, 2015), ou seja 7,5\% da população do estado do Rio de Janeiro (cerca de $6 \%$ no NF e apenas $1,5 \%$ no NOF). Esta população depende de muitos serviços ambientais proporcionados pelas áreas protegidas. As UCs podem proporcionar serviços ambientais essenciais, como a diminuição das secas, enchentes e erosão do solo, problemas ambientais recorrentes nesta mesorregião.

As UCs são o principal mecanismo de proteção da biodiversidade em todo o mundo. A criação dessas unidades traz benefícios para toda a sociedade, protegendo mananciais de água, ajudando a regular o clima, contendo erosões, promove o lazer e hábitos culturais da população e, principalmente, fomenta o desenvolvimento sustentável. O reconhecimento dos benefícios da UCs pela população é essencial para legitimar a busca e a consolidação de diferentes mecanismos para o seu financiamento e métodos de gestão (ARAÚJO, RODRIGUES E SANTOS, 2009).

Existem muitos problemas a serem superados para que o Sistema Nacional de Unidades de Conservação seja consolidado. Entre esses problemas, muitos autores citam a falta de planejamento a longo prazo, a pressão de uso sobre os recursos naturais, dificuldade na preservação dos processos que mantém a diversidade biológica, conflitos com as populações humanas que vivem no interior e no entorno das UCs, a necessidade de recursos humanos para fiscalizá-las e o aporte mais significativo de recursos financeiros (MEDEIROS, 2006; MMA, 2007; SOS MATA ATLÂNTICA, 2017). 


\section{Referências Bibliográficas}

ALMEIDA, D. Recuperação Ambiental Da Mata Atlântica. Editus, 3ª ed., 2016.

ARAÚJO, F.F.S.; RODRIGUES, C.G.O.; SANTOS, F.P. Desafio do financiamento da conservação da natureza no Brasil. Desafios do Desenvolvimento, 55, 2009.

BARLOW, J. et al. The future of hyperdiverse tropical ecosystems. Nature, 559, 517-526, 2018.

BRASIL. Constituição (1998). Constituição da República Federativa do Brasil. Brasília, DF: Senado Federal: Centro Gráfico, 292p., 1988.

BRASIL, Novo Código Florestal Brasileiro, Lei n 12.651, de 25 de maio de 2012. Lei de Proteção da Vegetação Nativa, 2012.

BRASIL. Decreto no 4.340, de 22 de agosto de 2002. Regulamenta artigos da Lei no 9.985, de 18 de julho de 2000, que dispõe sobre o Sistema Nacional de Unidades de Conservação da Natureza - SNUC, e dá outras providências. Diário Oficial, Brasília, DF, 22 ago. 2002. Disponível em: http://www.planalto.gov.br/ccivil_03/decreto/2002/d4340.html Acesso em:29 nov. 2017.

BRASIL. Decreto no 5.746, de 05 de abril de 2006. Regulamenta o art. 21 da Lei no 9.985, de 18 de julho de 2000, que dispõe sobre o Sistema Nacional de Unidades de Conservação da Natureza. Diário Oficial, Brasília, DF, 05 abr. 2006. Disponível em: http://www.planalto.gov.br/ ccivil_03/_ato2004-2006/2006/decreto/d5746.htm Acesso em: 29 nov. 2017.

BRASIL. Lei no 9.985, de 18 de julho de 2000. Regulamenta o art. 225, § 10, incisos I, II, III e VII da Constituição Federal, institui o Sistema Nacional de Unidades de Conservação da Natureza e dá outras providências. Diário Oficial da República Federativa do Brasil. Brasília, DF, 18 jul. 2000. Disponível em: http://www.planalto.gov.br/ccivil_03/leis/L9985.htm. Acesso em: 29 nov. 2017.

BRASIL. Ministério do Meio Ambiente. Acesso em 22 de Novembro de 2017. Disponível em: < http://mapas.mma.gov.br/i3geo/datadownload.htm>. 2017.

BRASIL. Ministério do Meio Ambiente. Informe Nacional sobre Áreas Protegidas no Brasil. Brasília: MMA, 124p., 2007.

BRASIL. Ministério do Meio Ambiente. SNUC - Sistema Nacional de Unidades de Conservação da Natureza: Lei no 9.985, de 18 de julho de 2000; Decreto $n^{\circ} 4.340$, de 22 de agosto de 2002; Decreto $n^{\circ} 5.746$, de 5 de abril de 2006. Plano Estratégico Nacional de Áreas Protegidas: Decreto n० 5.758, de 13 de abril de 2006. Brasília: MMA, 76 p., 2011.

BRITO, R.O.; MARQUES, C.F. Pagamento por serviços ambientais: uma análise do ICMS ecológico nos estados brasileiros. Planejamento e Políticas Públicas, 49, 357-383, 2017.

BUTCHART, S.H.M.; WALPOLE, M.; COLLEN, B., et al. Global Biodiversity: Indicators of Recent Declines. Science. V. 328. 28 may, 2010.

CAMARGO, A. et al. Os desafios da sustentabilidade no período pós-Rio-92: uma avaliação da situação brasileira. In: CARMARGO, A. et al. Meio ambiente no Brasil: avanços e obstáculos pós-Rio 92. São Paulo: Estação Liberdade, 1, 21-40, 2002.

CAMPANILI, M.; PROCHNOW, M. Mata Atlântica uma rede pela floresta. RMA, 1a ed., 2006.

CAMPHORA, A.L.; MAY, P.H. A valoração ambiental como ferramenta de gestão em unidades de conservação: há convergência de valores para o bioma Mata Atlântica? Megadiversidade, 2, 1-12, 2006. 
CASTRO, P.F. Atlas das unidades de conservação do estado do Rio de Janeiro. Metalivros, $2^{\mathrm{a}}$ ed., p. 35, 2015.

COELHO, M.A.N.; BAUMGRATZ, J.F.A., LOBÃO, A.Q., SYLVESTRE, L.S., TROVÓ, M., ESTEVÃO, L.A.S. Flora do estado do Rio de Janeiro: avanços no conhecimento da diversidade. Rodriguésia, 68 (1), 1-11, 2017.

CONTI, B.R. Uma análise sobre o papel do ICMS-Ecológico como instrumento de gestão da biodiversidade e promoção do turismo nas unidades de conservação. Observatório de Inovação do Turismo - Revista Acadêmica, 9 (2), 40-65, 2017.

CUNHA, A.A.; GUEDES, F.B. Mapeamento para a conservação e recuperação da biodiversidade na Mata Atlântica: em busca de uma estratégia espacial integradora para orientar ações aplicadas. Instituto do Meio Ambiente e dos Recursos Naturais Renováveis, 2013.

ESRI. Shapefile Technical Description, Jul. 1998.

FIRJAN. Retratos Regionais: Perfil econômico regional: região Noroeste Fluminense. Firjan, $6^{\mathrm{a}}$ ed., 2015.

FORZZA, R.C.; BAUMGRATZ, J.F.A.; BICUDO, C.E.M; CARVALHO JR., A.A.; COSTA, A.; COSTA, D.P.; HOPKINS, M.; LEITMANN, P.M.; LOHMANN, L.G.; MAIA, L.C.; MARTINELLI, G.; MENEZES, M.; MORIM, M.P.; COELHO, M.A.N.; PEIXOTO, A.L.; PIRANI, J.R.; PRADO, J.; QUEIROZ, L.P.; SOUZA, V.C.; STEHMANN, J.R.; SYLVESTRE, L.S.;WALTER, B.M.T. \& ZAPPI, D. Catálogo de plantas e fungos do Brasil. 2 vols. Andrea Jakobsson Estúdio Editorial/Jardim Botânico do Rio de Janeiro, 2010.

GARAY, I.; BECKER, B. (Orgs). Dimensões humanas da biodiversidade: o desafio de novas relações sociedade - natureza no século XXI. Petrópolis, p.159-184, 2006.

GELUDA, L.; YOUNG, C.E.F. Financiando o Éden: Potencial Econômico e Limitações da Compensação Ambiental Prevista na Lei do Sistema Nacional de Unidades de Conservação da Natureza. In: IV Congresso Brasileiro de Unidades de Conservação. ANAIS. Rede Nacional Pró-unidades de Conservação / Fundação O Boticário de Proteção à Natureza. Curitiba, 2004.

GURGEL H.C. et al. Unidades de conservação e o falso dilema entre conservação e desenvolvimento in MEDEIROS, Rodrigo. ARAÚJO, Fábio França Silva (Org.). Dez anos do Sistema Nacional de Unidades de Conservação da Natureza: lições do passado, realizações presentes e perspectivas para o futuro. Brasília: MMA, p.37-53, 2011.

HAAG, C. Entre o homem e a natureza. Pesquisa Fapesp, 176, 86-89, 2010.

IBGE - Mapa de Vegetação do Brasil. Diretoria de Geociências. IBGE - Instituto Brasileiro de Geografia e Estatística. 2a Ed. Rio de Janeiro - RJ, 2000.

ICMBio/MMA. Instituto Chico Mendes de Biodiversidade/Ministério do Meio Ambiente. Livro vermelho da fauna brasileira ameaçada de extinção. Volume l, $1^{\text {a }}$ ed., 2018.

JEPSON, P. R.; CALDECOTT, B.; SCHMITT, S. F.; et al. Protected area asset stewardship. Biological Conservation, 212 (A), 183-190, 2017.

LEUZINGER, M.D. Uso Público em Unidades de Conservação. Congresso de Direito Ambiental da PUC-RIO, Rio de Janeiro, 2010.

LOPES, J.G.; VIALÔGO, T.M.L. Unidades de Conservação no Brasil. Revista JurisFIB-Volume IV- Ano IV-dezembro 2013.

LINS-DE-BARROS, F.M. Integrated coastal vulnerability assessment: A methodology for coastal cities management integrating socioeconomic, physical and environmental dimensions - Case study of 
Região dos Lagos, Rio de Janeiro, Brazil. Ocean \& Coastal Management, 149, 1-11, 2017.

LONDE, P.R.; MENDES, P.C. A influência das áreas verdes na qualidade de vida urbana. Hygeia 10 (18), 264-272, 2014.

MARTINELLI, G.; MORAES, M.A. Livro vermelho da flora do Brasil. Andrea Jakobsson Estúdio Editorial/ Jardim Botânico do Rio de Janeiro, 1ª ed., 2013.

MEDEIROS, R. Evolução das tipologias e categorias de áreas protegidas no Brasil. Ambiente \& Sociedade, 9 (1), 41-64, 2006.

MEDEIROS, R.; GARAY, I. Singularidades do sistema de áreas protegidas no Brasil e sua importância para a conservação da biodiversidade e o uso sustentável de seus componentes. In: Garay e Becker eds. Dimensões humanas da biodiversidade: o desafio de novas relações sociedade-natureza no século XXI. Ed. Vozes, 1ª.ed., p. 159-184, 2006.

MEDEIROS, R.; YOUNG, C.E.F.; PAVESE, H.B.; ARAÚJO, F.F.S. Contribuição das unidades de conservação brasileiras para a economia nacional: Relatório Final. Brasília: UNEP-WCMC, 2011.

MEDEIROS, R. A Proteção da Natureza: das Estratégias Internacionais e Nacionais às demandas locais. Rio de Janeiro: UFRJ-PPG., 391p. Tese (Doutorado em Geografia), 2003.

MILANO, M.S. Mitos no manejo de unidades de conservação no Brasil, ou a verdadeira ameaça. Anais do Congresso Brasileiro de Unidades de Conservação, Campo Grande, Brasil, v.1, p.11-25, 2000 .

MMA - MINISTÉRIO DO MEIO AMBIENTE. Áreas prioritárias para a conservação, uso sustentável e repartição de benefícios da biodiversidade brasileira: atualização - portaria MMA no 9, de 23 de janeiro de 2007. Ministério do Meio Ambiente, Secretaria de Biodiversidade e Florestas, $1^{\text {a }}$ ed., 300p., 2007.

MMA - MINISTÉRIO DO MEIO AMBIENTE. Bacias Hidrográficas. http://www.mma.gov.br/agua/ bacias-hidrograficas. Acesso em outubro de 2018.

MMA - MINISTÉRIO DO MEIO AMBIENTE. Download de dados geográficos. Disponível em: http:// mapas.mma.gov.br/i3geo/datadownload.htm. Acesso em 2019.

NOSSO FUTURO COMUM (Relatório Brundtland). Comissão Mundial sobre o Meio Ambiente e Desenvolvimento. Rio de Janeiro: Editora da Fundação Getúlio Vargas, 1988.

OLIVEIRA, J.C.C.; BARBOSA, J.H.C. Roteiro para criação de unidades de conservação municipais. Brasília, DF: Ministério do Meio Ambiente, 68 p. 2010.

PRIMACK, R.B.; RODRIGUES, E. Biologia da Conservação. Editora Planta, Londrina, 327 p, 2015.

RYLANDS, A.B.; BRANDON, K. Unidades de Conservação Brasileira. Megadiversidade. Vol 1, n 1. 2005.

SACHS, I. Prefácio in VEIGA, J. E. Desenvolvimento Sustentável: o desafio do século XXI. 3ed. Rio de Janeiro: Garamond, p. 9-12, 2008.

SEA - SECRETARIA DE ESTADO DO AMBIENTE. Abrace essas dez! Defenda todas as espécies ameaçadas de extinção. Rio de Janeiro, SEA, $1^{\text {a }}$ ed., 2015.

SEBRAE. Painel regional: Norte Fluminense. Observatório Sebrae/RJ, 1ª ed., 2015.

SILVA, A.P.V. Os efeitos do ICMS ecológico para as políticas ambientais dos municípios fluminenses. Tese do Programa de Pós Graduação em Políticas Públicas, Estratégias e Desenvolvimento, UFRJ, Rio de Janeiro, 239p., 2018. 
SLUYS, M.V. Projeto Pequeno: Biodiversity conservation of the restingas in the state of Rio de Janeiro, Brazil. http://www.cepf.net/Documents/final_biomas.pdf. Acesso em abril de 2017.

SOS MATA ATLÂNTICA. Unidades de conservação municipais da Mata Atlântica. Fundação SOS Mata Atlântica, 103p., 2018.

TEIXEIRA, M.S.G; MEDEIROS, A.A; SILVA, J.G. O processo de gestão ambiental em unidades de conservação da natureza: um estudo de caso no Parque Estadual Dunas de Natal. XII SIMPEP Bauru, SP, Brasil. 2005.

TEIXEIRA, M.C.; SCHOEREDER, J.H.; MAYHÉ-NUNES, A.J. Geographic distribution of Atta robusta Borgmeier (Hymenoptera: Formicidae). Neotropical Entomology, 32 (4), 719-721, 2003.

TORRES, D.F.; OLIVEIRA, E.S. Percepção Ambiental: Instrumento para Educação Ambiental em Unidades de Conservação. Ver. Eletrônica. Mestr. Educ. Ambient. ISSN 1517-1256, v.21, julho a dezembro de 2008.

VILLA, E.B. Diagnóstico participativo e enquadramento ao PRONAF Florestal de agricultores familiares de Mata Atlântica em duas regiões do Estado do Rio de Janeiro. [Mestrado] Instituto de Florestas, Universidade Federal Rural do Rio de Janeiro, 84p, 2006. 